\title{
Identifying and decomposing peer effects on decision-making using a randomized controlled trial
}

\author{
Daichi Shimamoto ${ }^{1}$ (D) Yasuyuki Todo ${ }^{2} \cdot$ Yu Ri Kim ${ }^{3} \cdot$ Petr Matous M $^{4}$
}

Received: 24 April 2020 / Accepted: 3 October 2021 / Published online: 13 November 2021

(c) The Author(s) 2021

\begin{abstract}
Utilizing a randomized controlled trial (RCT) in traditional clusters of apparel and textile firms in Vietnam, this paper investigates peer effects on firm managers' decisions to participate in seminars on export promotion. We invited 131 randomly selected firm representatives to three one-day seminars on export promotion. We use the number of randomly invited peers to identify peer effects. We further decompose the invited peers into peers invited to the same seminar, those invited to the earlier seminars, and those invited to the later seminars. We find that the former has a positive effect on firms' participation, whereas the latter two have no significant effect. These results imply that peer effects on participation primarily arise from the benefits of face-to-face interactions. The presence of positive peer effects suggests that multiple equilibria in terms of the share of participants within each village of firms may emerge, which is also consistent with our observations.
\end{abstract}

Keywords Peer effects · Social networks · Information confirmation ·

Word-of-mouth $\cdot$ Free riding $\cdot$ Randomized controlled trials

JEL code C93 - D22

Daichi Shimamoto

d.shimamoto@eco.kindai.ac.jp

1 Faculty of Economics, Kindai University, 3-4-1 Kowakae, Higashiosaka City, Osaka 577-8502, Japan

2 Graduate School of Economics, Waseda University, 1-6-1 Nishi-Waseda, Shinjuku-ku, Tokyo 169-0051, Japan

3 Asia-Pacific Research Center, Hanyang University, 222 Wangsimni-ro, Sageun-dong, Seongdong-gu, Seoul, Korea

4 Department of Civil Engineering, School of Engineering, The University of Tokyo, Tokyo, Japan

5 Complex Systems Research Group, Faculty of Engineering and IT, The University of Sydney, Sydney, NSW 2006, Australia 


\section{Introduction}

Peer effects - that is, the effects of peers' behavior on actors' own behavior through social networks - have been recognized in the theoretical and empirical economics literature (Blume et al. 2011; Jackson and Zenou 2015). Although many studies have examined peer effects on economic activity, such as student performance (Sacerdote 2001; Zimmerman 2003; Angrist and Lang 2004; Calvó-Armengol et al. 2009), one strand of this literature focuses on peer effects on the decision to participate in social programs. For example, Duflo and Saez (2003) analyzed the role of social interactions in employees' decision to enroll in a retirement plan. They conducted an experiment in which they provided randomly selected employees with monetary incentives to participate in information fairs, and they found a positive peer effect on participation.

Peer effects may affect participation in social and business programs, particularly in programs focused on information dissemination, for four reasons. First, actors may be more likely to participate in a program if their peers also participate because actors may obtain the benefits of face-to-face interactions, which include having an enjoyable time with peers and lowering psychological barriers to participation. Second, peers' participation encourages actors to participate if they expect to be able to discuss the information provided in a program with these peers and thus to enhance their understanding of the information. This channel is related to Centola's (2010) findings from a social experiment showing that people are more likely to adopt new health behaviors when a group's online social network is dense, i.e., when most of a group's members know one another. Centola (2010) interpreted this finding to indicate that the reinforcement of the same knowledge by multiple peers results in a deeper understanding of the knowledge and thus promotes its adoption. We refer to this channel as information confirmation. Third, peers' participation discourages actors' participation in programs because actors may be able to obtain the information that their peers receive in the program at no personal cost. We refer to this channel as information free riding. Fourth, those who participated in a program may encourage or discourage their peers from participating in the same program on the following days depending on its content and quality. We refer to this channel as word-of-mouth. In short, the benefits of face-to-face interactions and information confirmation result in positive peer effects, whereas free riding results in negative peer effects. However, whether word-of-mouth results in positive peer effects or negative effects depends on the seminar content and quality.

Whether peer effects are positive or negative largely affects the participation rate in a seminar. On the one hand, if positive peer effects dominate because of the benefits of face-to-face interactions and information confirmation, actors' gain from participation depends on whether their peers participate. If actors believe that their peers will not participate, they will not participate either. In this situation, few will participate. However, if they believe that their peers will participate, most of them will also participate. On the other hand, if negative peer effects dominate because of free riding, only a few actors participate, whereas others free ride and thus obtain the information provided in the seminar. In either case, peer effects may result in a low participation rate in programs for information dissemination. In practice, the take-up rate of social and business programs, particularly those in developing countries, is often quite low 
(Bertrand et al. 2004; Currie 2006; Bruhn and Zia 2013; McKenzie and Woodruff 2014).

Therefore, the empirical question of how peer effects work in such programs is relevant to both program organizers and policy makers. However, it is difficult to empirically identify peer effects both because of the reflection problem articulated by (Manski 1993). The reflection problem arises because average group behaviors are a mirror image of individual behaviors. Thus, it is difficult to identify causality from the correlations between behaviors.

To accurately identify peer effects, recent studies have utilized natural and randomized experiments on peer formation and participant selection (Duflo and Saez 2003; Zimmerman 2003; Falk and Ichino 2006; De Giorgi et al. 2010; Aral and Walker 2011; Banerjee et al. 2013; Dahl et al. 2014; Sacerdote 2014; Cai and Szeidl 2018; Fafchamps and Quinn 2018). This study follows this literature on identifying peer effects based on randomized experiments. In particular, we conducted a randomized controlled trial (RCT) in which we invited randomly selected firm representatives from a population of registered small and medium-sized enterprises (SMEs) in 11 traditional garment and textile clusters in Vietnamese villages to seminars on export promotion. Before the RCT, we conducted a survey among all of these SMEs to capture the complete information exchange network of the firms within each cluster. The network peers were the information exchange partners solicited. In this setting, the number of firms' peers that are invited to the seminar can be considered as random given the number of peers. Thus, we identify peer effects by estimating the impact of the number of invited peers on managers' participation after controlling the number of peers. Since only invited firms can participate in the seminars, the effect of the number of peers that are invited to the seminar can be viewed as a good proxy for the effect of peers' participation on their own participation.

Furthermore, we identify two of the four types of peer effects mentioned earlier, i.e., those arising from benefits of face-to-face interactions and word-of-mouth, and test if the remaining two, i.e., information confirmation and information free riding, are jointly significant. In our experiment, we invited each participant to one of three one-day seminars held over three consecutive days. The invited firms were allocated to the three seminars randomly, and they were not allowed to change their participation date. Given this unique structure of our experiment, we can separately examine the effect of peers who are invited to the seminars before the seminar to which a firm is invited, of those who are invited to the seminar to which the firm is invited, and of those who are invited to the seminars after the seminar to which the firm is invited. The three types of peers would generate some of the four types of peer effects differently. Specifically, peers who were invited to the earlier seminars could affect the firm's decision maker through three channels, namely, word-of-mouth, information confirmation, and information free riding. Peers who were invited to the seminar on the same day could influence the decision maker through three channels, i.e., the benefits of face-to-face interactions, information confirmation, and information free riding. However, peers who were invited to the later seminars could affect the decision maker only in terms of information confirmation and information free riding. Therefore, the difference between the effect of peers invited to the earlier seminars and of those invited to the later seminars should constitute peer effects arising from 
word-of-mouth. Furthermore, the difference between the effect of those invited to the same seminar and of those invited to the later seminars should constitute peer effects attributable to the benefits of face-to-face interactions.

To preview our results, we find a positive, statistically significant, and quantitatively large effect of the number of peers who were invited to the seminar on the same day on firm managers' decision to participate in the seminar. However, neither the effect of the number of peers who were invited to the earlier seminars nor the effect of the number of peers who were invited to the later seminars is statistically significant. In addition, we reject the null hypothesis that the difference in the effect of the number of peers who were invited to the seminar on the same day and the effect of peers who were invited in the later seminars is zero. That is, the benefits of face-to-face interactions led to positive peer effects on participation in the seminar. However, the null hypothesis that the effect of the number of peers who were invited to the earlier seminars and the effect of peers who were invited to the later seminars are the same cannot be rejected. Thus, peer effects arising from word-of-mouth are found to be absent. Moreover, the sum of the positive effect due to information confirmation and the negative effect due to information free riding is not statistically significant, although we cannot further distinguish between the two.

Our results supporting positive peer effects, particularly those due to benefits of face-to-face communication, imply that the rate of firms' participation in the seminars may vary across villages, depending on the village characteristics that determine firms' beliefs about their peers' participation. We find evidence that supports this argument: there was a low participation rate (less than 40 percent) among 8 of the 11 villages in our sample, while the take-up rate was quite high (more than 50 percent) in others. This argument is also consistent with the literature finding that peer effects may lead to herd behaviors (Durlauf 2006; Blume et al. 2011; Bursztyn et al. 2014).

This study contributes to the literature on the identification of peer effects in the following four ways. First, although several papers, such as Cai and Szeidl (2018) and Fafchamps and Quinn (2018), examine peer effects on firms' performance and practices, this study is the first attempt to identify peer effects on firm managers' decisions to participate in business programs.

Second, we define peers according to firms' actual links to the exchange of business information. Most studies have defined peers according to group membership (Sacerdote 2001; Duflo and Saez 2003; Zimmerman 2003; De Giorgi et al. 2010). However, not all members of a particular group are necessarily closely connected for information or utility exchange, and it is therefore difficult to interpret the estimates from these studies (Carrell et al. 2011). Accordingly, some recent studies have defined peers more precisely, using data for social networks (Falk and Ichino 2006; CalvóArmengol et al. 2009; Aral and Walker 2011; Banerjee et al. 2013; Card and Giuliano 2013). The current study follows this strand of the literature and identifies all peer firms within the cluster with which firms exchange business information by asking firm representatives directly.

Third, we separately estimate several types of peer effects, particularly finding positive effects arising from the benefits of face-to-face interactions. A decomposition of peer effects into those from social learning and those from social utility is provided by Bursztyn et al. (2014), who examined how individuals' decisions to purchase a 
financial asset affect their peers' decisions. Our findings provide new light in the literature on the decomposition of peer effects.

In addition to making an academic contribution, this study can contribute to policy making. The take-up ratio of business and social programs is often low despite these programs' potential benefits. This study implies that program organizers can spatially focus their interventions and invite dense cliques of firms to increase the participation rate.

The rest of the paper is organized as follows. Section 2 describes the data and RCT. Section 3 presents the empirical methodology and the results, and Sect. 4 provides a discussion of the results and conclusions.

\section{Data and randomized experiment}

\subsection{Sampling and survey}

In this study, we focus on SMEs in village-based apparel and textile industry clusters in the Red River Delta surrounding Hanoi, the capital city of Vietnam. Village industry clusters are traditionally developed agglomerations of SMEs, including microenterprises in a particular industry such as apparel, wood furniture, or ceramics, within the village boundary. We focus on village industry clusters because it allows us to observe all networks within the village through which firms exchange business information. We have a substantial interest in export promotion through information seminars, and therefore, we target SMEs in the apparel and textile industry. Since the ratification of the US-Vietnam Bilateral Trade Agreement in 2001 and resulting reductions in tariffs, including those on apparel and textiles, exports of these products from Vietnam to the US have drastically increased. However, SMEs in traditional village clusters lag behind. In our sample explained later in detail, only approximately 10 percent of SMEs exported their products. This is possibly because of the lack of information about the procedures of exporting and foreign markets. Using the same experiment and data as used in this study, Kim et al. (2018) find that the exporting promotion seminar encourages relatively large firms among the targeted SMEs to export, implying that the seminar successfully provides important information for targeted SMEs to start exporting. Therefore, these institutional backgrounds are suitable for the objectives of this study.

We identified the village clusters using data from the Vietnam Enterprise Survey (VES), which was conducted by the General Statistical Office of Vietnam (GSO) in 2010. We chose villages or communes, which are the smallest administrative units, with more than five registered firms in the textile and apparel industries (industry codes 13 and 14 in the Vietnamese system of industry classifications) in the 10 provinces in the Red River Delta. Because not all of the firms are formally registered and because smaller firms in the VES are randomly selected, ${ }^{1}$ villages with more than five registered firms in the apparel and textile industry in the VES data are most likely to be industry

\footnotetext{
${ }_{1}$ The VES targets all firms with 30 employees or more and randomly selects 10 percent of firms with 10-29 employees.
} 
clusters of a specific industry. Through this process, we initially identified 19 villages in six provinces. We visited the selected villages and found that two villages among the 19 are not apparel and textile clusters, as most manufacturing firms in the villages do not necessarily engage in apparel or textile production. We also omitted one village from our sample both because it had already received business management training through another RCT and because it had been surveyed several times for impact evaluation (Higuchi et al. 2015). We assumed that firms in this village were already systematically different from firms in other villages.

Our study targeted registered firms in the remaining 16 apparel and textile village clusters. For each of the 16 villages, we obtained the full updated list of registered firms from the municipal governments. The total number of all registered firms in the target villages was 354. In December 2014 and January 2015, we requested faceto-face interviews with the owners, managing directors, and top-level managers of the 354 firms and obtained responses from 296, for a response rate of 84 percent. The questionnaire comprised questions on standard firm characteristics such as sales, the number of workers, main products, and ownership. In addition, to identify firm networks within a cluster, we presented to a representative of each firm the full list of registered firms in the village and asked him or her to list the firms with which the firm regularly exchanged business information. ${ }^{2}$ Because we surveyed most of the registered firms within a village, we identified a nearly complete network of registered firms within each village.

\subsection{Seminars on export promotion}

We conducted an RCT in which we randomly selected approximately half of the 286 firms that were surveyed and invited each of them to one of three one-day seminars on export promotion held from March 14 to March 16, 2015. The seminars consisted of four common classes on the following topics: introduction to the development of the global economy (delivered by a business school professor); basic exporting procedures (delivered by an official from the Vietnam Export Promotion Agency); advice for exporting to Japan (delivered by officials from the Hanoi office of the Japan External Trade Organization, JETRO); and finally, learning about the experiences of current exporters. The content of the seminars was slightly different across the three days: there was an additional class on e-customs on the second and third days, and there was a reception dinner after the seminar on the third day (Kim et al. 2018). However, we can disregard these differences when we estimate peer effects because the invitees were not informed about such differences upon invitation, and therefore,

\footnotetext{
2 The firms identified as the main business information exchange partners may depend on the respondent. All respondents were responsible decision makers of the surveyed firms, including owners, managing directors, and top-level managers. Admittedly, a top-level manager may not always know exactly whom the owner informally consults in business matters. However, given that most of the surveyed firms were family-run businesses, owners, managing directors and top-level managers are likely to be members of the same family who know each other well and have similar networks. To test this assumption, we separately interviewed one company owner and his wife, who was a top-level manager in the company, and their responses were identical.
} 
their decision to participate could not have been affected by the differences among the seminars.

The venue of the seminars was a three-star hotel located at the center of Hanoi. We chose a three-star hotel to attract participants. Traveling from the sample villages to the hotel took a minimum of $30 \mathrm{~min}$ by motorbike to a maximum of $2 \mathrm{~h}$ by bus. For several villages located far from the hotel, we chartered buses for the participants' transportation. We provided reimbursement for the cost of travel to participants who used their own means of transportation, such as public buses or motorbikes. Except for transportation cost reimbursement, no compensation was provided for participation except for meals at the hotel. We did not collect any participation fees from the participants.

\subsection{Selection and participation of firms}

We randomly selected 50 firms for the first day, 50 firms for the second day, and 51 firms for the third day (151 firms in total) using a stratified sampling strategy at the village level. Then, we sent an enumerator of the firm-level survey to personally invite each firm to the seminars and to deliver a formal letter that explained the details of the seminar. In the letter, we noted that only the owner, the managing director, or a top-level manager could participate in the seminars, although the seminar participants and respondents to our surveys may have differed. A few days before the seminars, we made phone calls to the firms to invite them again. If the firms were not willing to participate at the time of the first phone call, we made another phone call a day before the seminar. No firms were allowed to participate in the seminars unless they were invited, so there were no participants who had not been invited.

A small number of the invited firms participated in our seminars. Only 9 out of 50 firms participated on the first day, 15 out of 50 firms participated on the second day, and 14 out of 51 firms participated on the last day. In total, of the 151 invited firms, 38 firms participated; thus, the participation rate was 25.2 percent. This low participation rate is comparable to that of the business and financial literacy program conducted by Bruhn and Zia (2013) in Bosnia and Herzegovina.

\subsection{Construction of variables}

The dependent variable is a dummy variable that takes a value of one if firm $i$ participated in one of the three seminars and zero otherwise. The key independent variables are $I N V_{-} E A R L Y_{i}, I N V_{-} S A M E_{i}$, and $I N V_{-} L A T E R_{i}$, i.e., the number of firm $i$ 's peers invited to the earlier seminars, the number of its peers invited to the seminar on same days, and the number of its peers invited to the later seminars, respectively. Firm $i$ 's peers are defined as the firms that were reported by the survey respondent of firm $i$ as information-sharing partners or those that reported firm $i$ as an information-sharing partner. In network terms, this study utilizes undirected network data. Although our estimations are based on 131 invited firms with complete information, the number of peers is defined based on the information exchange partners of all of the registered 
firms within each village, including those that did not respond, those that were not invited, and those that were dropped due to missing information.

The control variables include firm attributes that contain the log of the total number of workers, the share of exports in total sales, the log of firm age, and the attributes of the top-level manager of each firm — such as the president or the owner-including the log of his or her age, the log of his or her years of education, and a dummy that indicates whether the respondent was female. The number of a firm's peers invited to the earlier seminars, INV_EARLY $Y_{i}$, is not observed for firms invited to the seminar on the first day. Similarly, the number of a firm's peers invited to the later seminars, $I N V_{-} L A T E R_{i}$, is not observed for firms invited to the seminar on the third day. We assign zero to these variables when these variables are not observed. To control for the effect of this procedure in the analysis, we include dummy variables that represent which seminar a firm was invited to in the estimated equations.

\subsection{Descriptive statistics}

When we construct the sample for our estimations, we dropped 6 firms in five villages in which the number of respondent firms was less than 3 so that the number of invited peers was mostly zero. We were forced to drop 14 firms that failed to report the survey information that was necessary for the estimations. Consequently, our baseline sample consists of 131 invited firms from 11 villages. Although the invited firms were not allowed to participate in a seminar that was different from the seminar to which they were invited, five invited firms attended a seminar to which they were not invited. For ethical reasons, we ultimately had to allow them to participate. In the analysis, we kept these five firms in the sample since the number of invited peers remains exogenous given the number of peers.

Table 1 analyzes whether we succeeded in randomizing the invitations we sent to the firms by conducting $t$ tests for systematic differences between the invited and noninvited firms in terms of the control variables for the firm and manager attributes used in the estimation. None of the variables showed a statistically significant difference between the two groups.

Table 2 shows the descriptive statistics of the variables that are used in later estimations for the sample of 131 firms. The average number of peers is 4.02 , of which approximately half, i.e., 1.98, were invited to one of the three seminars. Figure 1 shows the distribution of the number of peers and the number of invited peers, indicating their large variation. The average number of peers participating in any of the seminars is 0.62. Because the target firms are in traditional garment and textile clusters, the average number of workers, 25.99, is relatively small. On average, the share of exports in total sales is 19.0 percent, the firm age is 6.57 years, the age of managers is 42.9 years, and they have 13.8 years of education. Additionally, 19.8 percent of the managers are female. In the sample, 31.3, 35.1, and 33.6 percent of firms were invited to the seminar on the first, second, and third day, respectively. 
Table 1 Differences between invited and noninvited firms

\begin{tabular}{|c|c|c|c|c|c|c|c|c|}
\hline \multirow[t]{2}{*}{ Variable } & \multicolumn{3}{|c|}{ Invited firms } & \multicolumn{3}{|c|}{ Noninvited firms } & \multicolumn{2}{|l|}{ Difference } \\
\hline & $N$ & Mean & S.D & $N$ & Mean & S.D & Invited-noninvited & $p$-value \\
\hline \multicolumn{9}{|c|}{ Firm attributes } \\
\hline $\begin{array}{l}\text { Total } \\
\text { number } \\
\text { of peers } \\
\text { (degree) }\end{array}$ & 140 & 3.979 & 3.492 & 135 & 3.948 & 3.293 & 0.03 & 0.941 \\
\hline $\begin{array}{l}\text { Number } \\
\text { of } \\
\text { workers }\end{array}$ & 142 & 29.51 & 59 & 132 & 76.38 & 410.41 & -46.87 & 0.179 \\
\hline $\begin{array}{l}\text { Share of } \\
\text { exports } \\
\text { in total } \\
\text { sales }\end{array}$ & 146 & 19.58 & 37.75 & 136 & 14.74 & 32.38 & 4.84 & 0.250 \\
\hline Firm age & 144 & 8.681 & 5.467 & 136 & 8.61 & 6.01 & 0.07 & 0.919 \\
\hline \multicolumn{9}{|c|}{ Manager attributes } \\
\hline Age & 142 & 43.268 & 9.922 & 130 & 44.492 & 10.28 & -1.225 & 0.319 \\
\hline $\begin{array}{l}\text { Female } \\
\text { dummy }\end{array}$ & 146 & 0.192 & 0.395 & 138 & 0.217 & 0.414 & -0.026 & 0.594 \\
\hline $\begin{array}{l}\text { Years of } \\
\text { school- } \\
\text { ing }\end{array}$ & 142 & 13.831 & 2.134 & 133 & 14.083 & 2.306 & -0.252 & 0.348 \\
\hline
\end{tabular}

$\mathrm{N}$ and S.D. represent the number of observations and standard deviation, respectively

\section{Estimation methods and results}

\subsection{Total peer effects}

When we estimate peer effects on firm managers' participation decisions in seminars, there are several challenges to identifying peer effects. First, the largest challenge is that it is difficult to identify peer effects because of the reflection problem (Manski 1993). That is, because firms' participation decisions would affect each other, the decisions of a particular firm's peers, which is a determinant of the firm's decision, are a function of the firm's decision. Therefore, the regression of the firm's participation on its peers' participation would create a mechanical endogeneity because peers' participation would capture the firm's own participation, which would bias the estimated coefficients.

To address the biases caused by reflection, we employ the number of peers who were randomly invited to the seminars as the key independent variable in ordinary least squares (OLS) estimations. Because the number of each firm's peers invited to the seminars is randomly determined once the total number of its peers is controlled for, we can avoid the endogeneity arising from the reflection problem in regressions where the number of invited peers and the total number of peers are simultaneously 
Table 2 Descriptive statistics

\begin{tabular}{|c|c|c|c|c|}
\hline Variable & Mean & S.D & Min & $\operatorname{Max}$ \\
\hline Participation dummy & 0.252 & 0.436 & 0.000 & 1.000 \\
\hline Number of peers (degree) & 4.015 & 3.517 & 0.000 & 16.000 \\
\hline Number of invited peers & 1.977 & 1.895 & 0.000 & 7.000 \\
\hline on earlier days & 0.664 & 1.020 & 0.000 & 4.000 \\
\hline on the same day & 0.649 & 0.793 & 0.000 & 3.000 \\
\hline on later days & 0.664 & 1.100 & 0.000 & 6.000 \\
\hline Dummy for peers' invitation to the seminar & 0.725 & 0.448 & 0.000 & 1.000 \\
\hline No-peer dummy & 0.168 & 0.375 & 0.000 & 1.000 \\
\hline Number of unregistered peers and peers outside the cluster & 0.183 & 0.605 & 0.000 & 4.000 \\
\hline Eigenvector centrality & 0.359 & 0.326 & 0.000 & 1.000 \\
\hline Betweenness centrality & 0.029 & 0.043 & 0.000 & 0.241 \\
\hline Closeness centrality & 0.199 & 0.157 & 0.016 & 0.706 \\
\hline \multicolumn{5}{|l|}{ Invitation day } \\
\hline Dummy for an invitation to the seminar on the first day & 0.313 & 0.465 & 0.000 & 1.000 \\
\hline Dummy for an invitation to the seminar on the second day & 0.351 & 0.479 & 0.000 & 1.000 \\
\hline Dummy for an invitation to the seminar on the third day & 0.336 & 0.474 & 0.000 & 1.000 \\
\hline \multicolumn{5}{|l|}{ Firm attributes } \\
\hline Number of workers & 25.985 & 56.466 & 0.000 & 500.000 \\
\hline Share of exports in total sales & 19.031 & 37.370 & 0.000 & 100.000 \\
\hline Firm age & 8.695 & 5.368 & 1.000 & 26.000 \\
\hline \multicolumn{5}{|l|}{ Manager attributes } \\
\hline Age & 42.878 & 9.794 & 25.000 & 69.000 \\
\hline Female dummy & 0.198 & 0.400 & 0.000 & 1.000 \\
\hline Years of education & 13.832 & 2.131 & 9.000 & 18.000 \\
\hline \multicolumn{5}{|l|}{ Invited peers' average firm attributes } \\
\hline Average number of peers & 4.772 & 3.794 & 0.000 & 13.500 \\
\hline Number of workers & 2.174 & 1.564 & 0.000 & 5.227 \\
\hline Share of exports in total sales & 12.359 & 29.978 & 0.000 & 100.000 \\
\hline Firm age & 6.572 & 5.245 & 0.000 & 21.000 \\
\hline \multicolumn{5}{|l|}{ Invited peers' average manager attributes } \\
\hline Age & 32.050 & 20.946 & 0.000 & 65.000 \\
\hline Female dummy & 0.103 & 0.216 & 0.000 & 1.000 \\
\hline Years of education & 9.997 & 6.308 & 0.000 & 18.000 \\
\hline
\end{tabular}

$\mathrm{N}=131$. S.D. represents standard deviation 
Fig. 1 Distribution of the number of peers
Panel (a): The number of peers

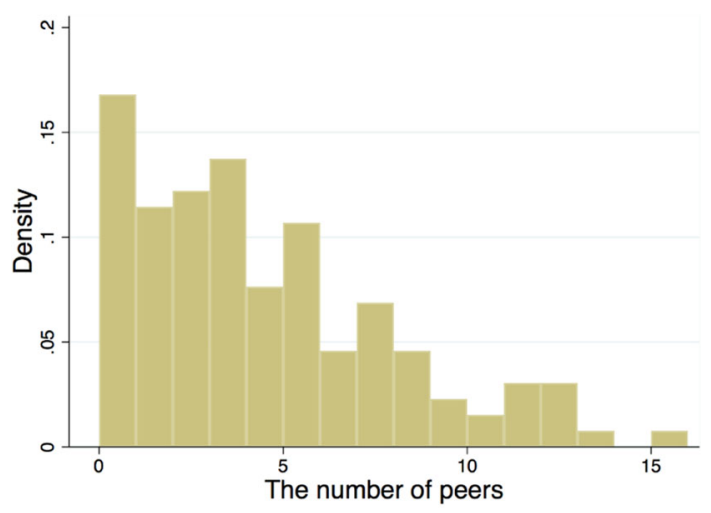

Panel (b): The number of peers invited to the seminars

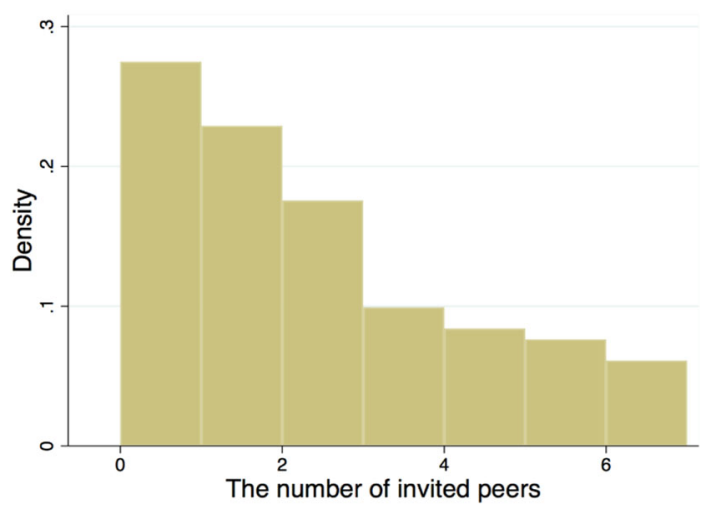

used as independent variables. A more intuitively plausible way is to use the number of invited peers as an instrumental variable (IV) for the number of participating peers in IV estimations. Then, the coefficient of the number of participating peers can be easily interpreted as the effect of peer behaviors on one's own behavior. However, given the small sample in this study, IV estimates may be quite biased. Therefore, we employ the OLS approach using the number of invited peers rather than IV using the number of participating peers. Although the number of invited peers does not directly represent peers' behaviors, its effect on the firm's participation can be viewed as a good proxy for the effect of peers' behaviors on own behavior because only invited firms can participate in the seminars and our OLS approach is a reduced form of the IV approach in which the number of participating peers directly represents peers' behaviors. It should be noted that the effect of the number of invited peers should be smaller than the effect of the number of participating peers because the former is diluted by invited but nonparticipating peers.

The second source of bias in the estimation of peer effects is the correlated effects of Manski (1993) or the correlation between unobservable attributes shared by an actor 
and its peers, such as common knowledge, willingness to learn, aspiration to export, culture, and their behaviors. Such unobservable attributes arise mostly because of endogenous formation of peers. If the unobservable common attributes or common shocks to a group are not controlled for, they are included in the error term and thus lead to another type of endogeneity in peer participation (Bramoullé et al. 2009, 2020).

To address the issue of correlated effects, we control for village fixed effects in the estimated equations. Since the village fixed effects pick up common unobservable characteristics shared by all firms in the village, village fixed effects control for correlated effects to some extent. However, if firms connected to each other have a similar propensity to participate in the seminar due to correlated unobserved characteristics shared by peer firms, the estimation of peer effects is still biased due to correlated effects even if we control for village fixed effects. To check whether correlated effects bias the estimation of peer effects using village fixed effects, our alternative specification drops firms that have no peer from the sample and uses network cluster fixed effects, i.e., fixed effects for firms connected directly or indirectly with each other within the village, instead of village fixed effects.

Finally, the estimation of peer effects can be biased by the exogenous effect of Manski (1993) or the direct effect of peers' attributes on the firm's behavior. In particular, in the settings of this study, we presume that firm managers may decide whether or not they participate in the seminars, partly depending on the attributes of other invited firms and firm managers. For example, if invited peer firms of a firm are large in size or their managers are male, the firm may be more willing to participate in the seminars. To control for the exogenous effect, we include the average attributes of invited peers of the focal firm in the set of independent variables. Based on these arguments, we consider the following linear probability model:

$$
\begin{aligned}
P A R_{i l}= & \alpha_{l}+\beta I N V_{i l}+\delta n_{i l}+\gamma X_{i l}+\zeta D a y_{i} \\
& +\lambda \sum_{j \in P_{i l}} X_{j l} / n_{i l}+\varepsilon_{i l}
\end{aligned}
$$

where $P A R_{i l}$ is a dummy variable for the participation of firm $i$ in village $l$ in the invited seminar and $P_{i l}$ represents the set of firm $i$ 's invited peers in village $l$. The first term on the right-hand side, $\alpha_{l}$, is the village fixed effect. The second term, $I N V_{i l}$, is the number of firm $i$ 's peers in village $l$ invited. Thus, $\beta$ represents the effect of peers who were invited to the seminars on the firm manager's participation decision. We refer to this effect as total peer effects. The third term, $n_{i l}$ is the number of peers of firm $i$. The number of invited peers of firm $i, I N V_{i l}$, can be seen as good as random after controlling the number of peers, while the number of peers of firm $i$ is endogenously determined. The fifth term, $D a y_{i}$, is dummies that indicate on which day firm $i$ is invited to the seminar. The sixth term, $\sum_{j \in P_{i}} X_{j l} / n_{i l}$, is a vector of the average attribute of invited firm $i$ 's peers. Thus, $\lambda$ represents the exogenous effect, as argued by Manski (1993). The seventh term, $\varepsilon_{i l}$, is the error term.

The result from the OLS estimation of Eq. (1) is shown in column (1) in Table 3. The estimated coefficient on the number of invited peers is positive but not statistically significant. Next, we dropped 22 firms that have no peer from the sample and use 


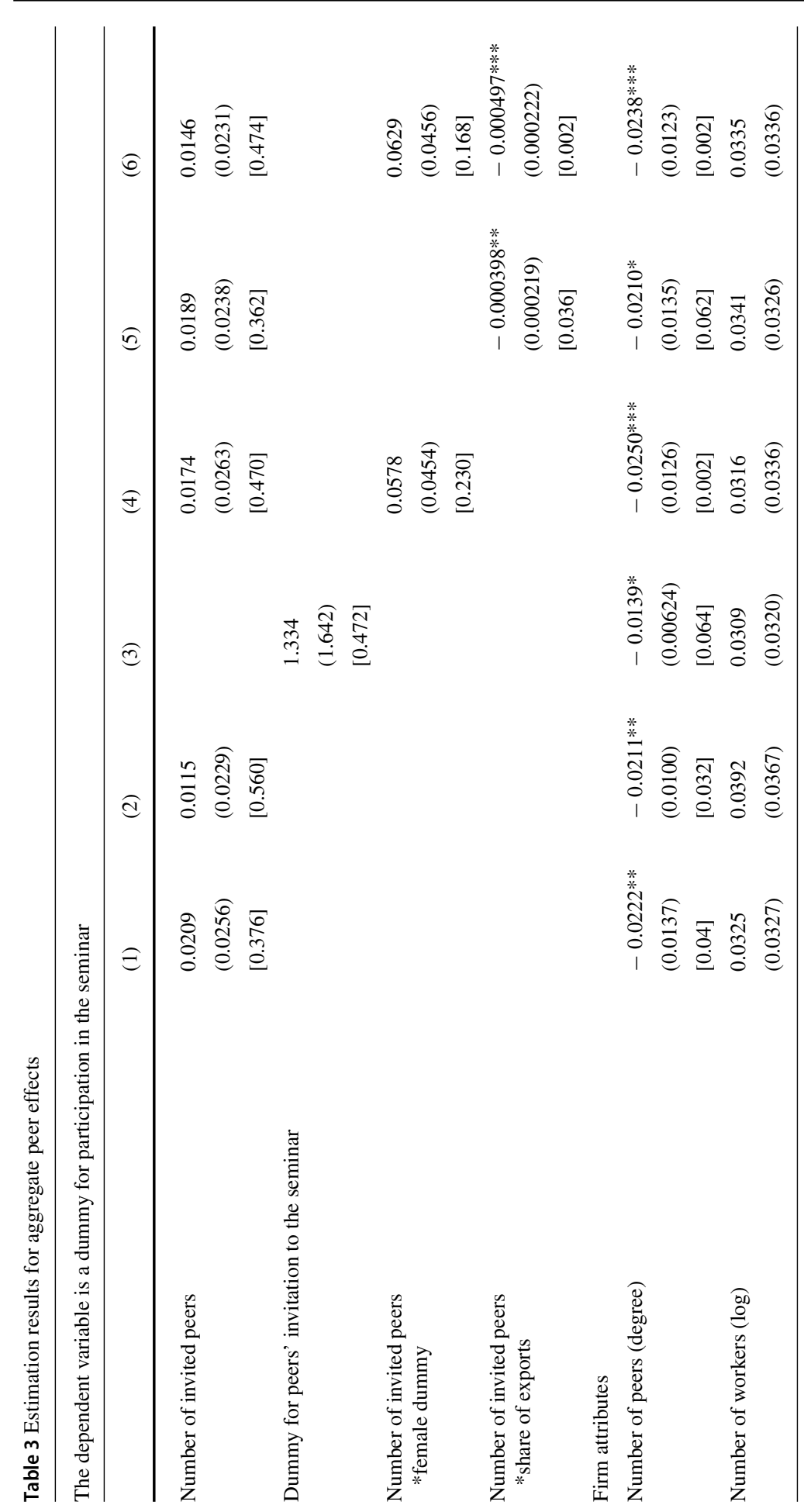




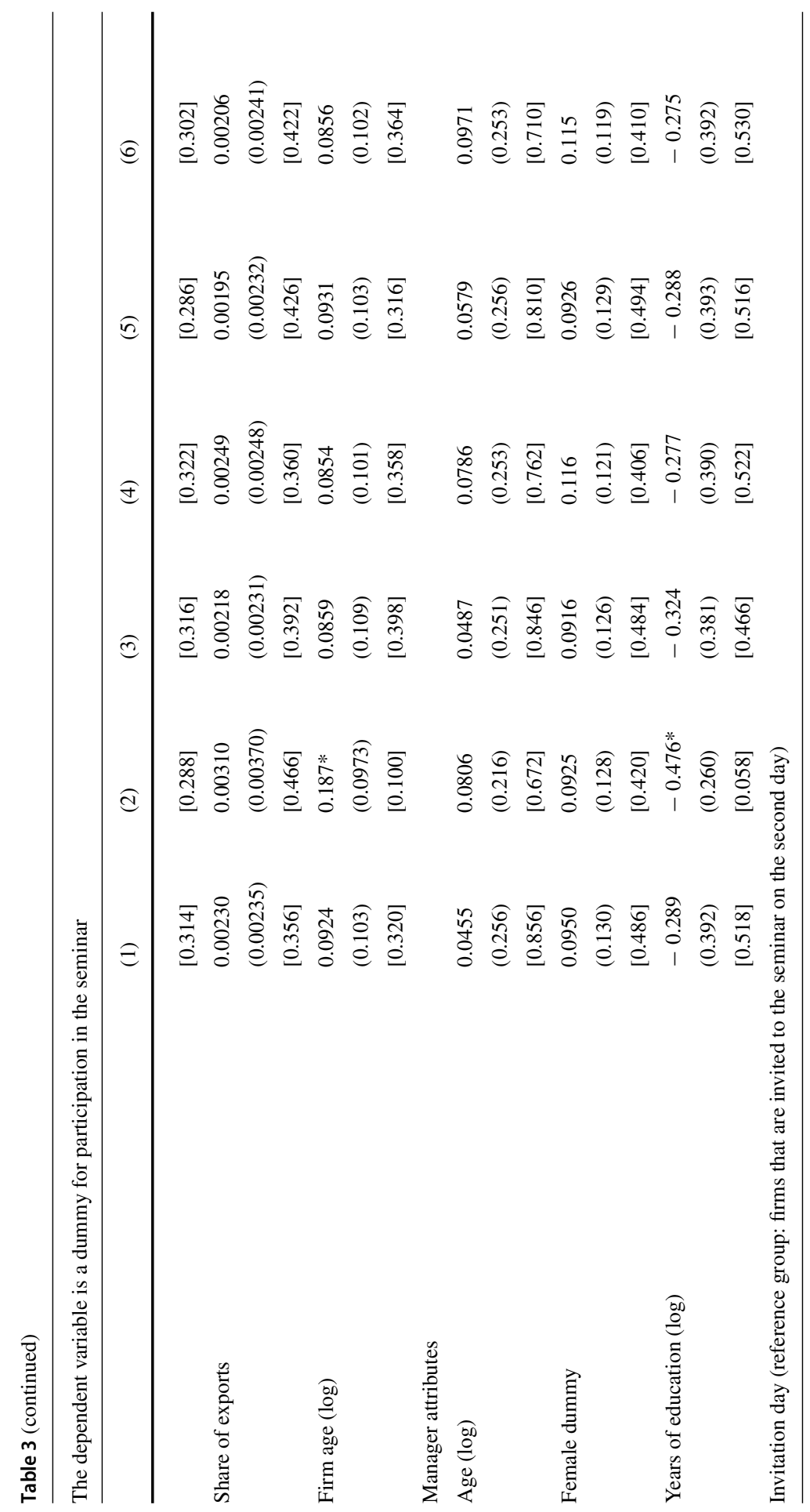




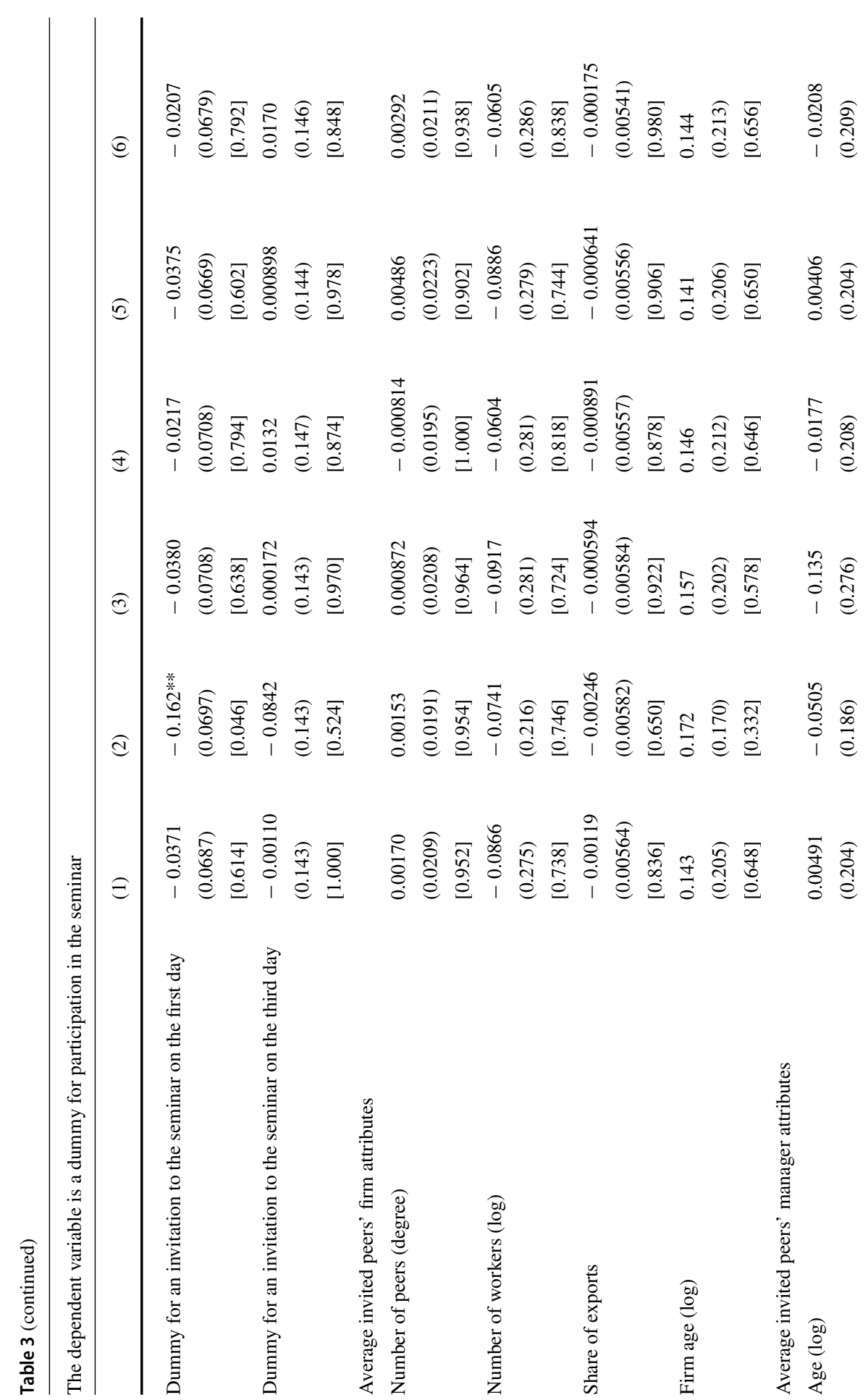




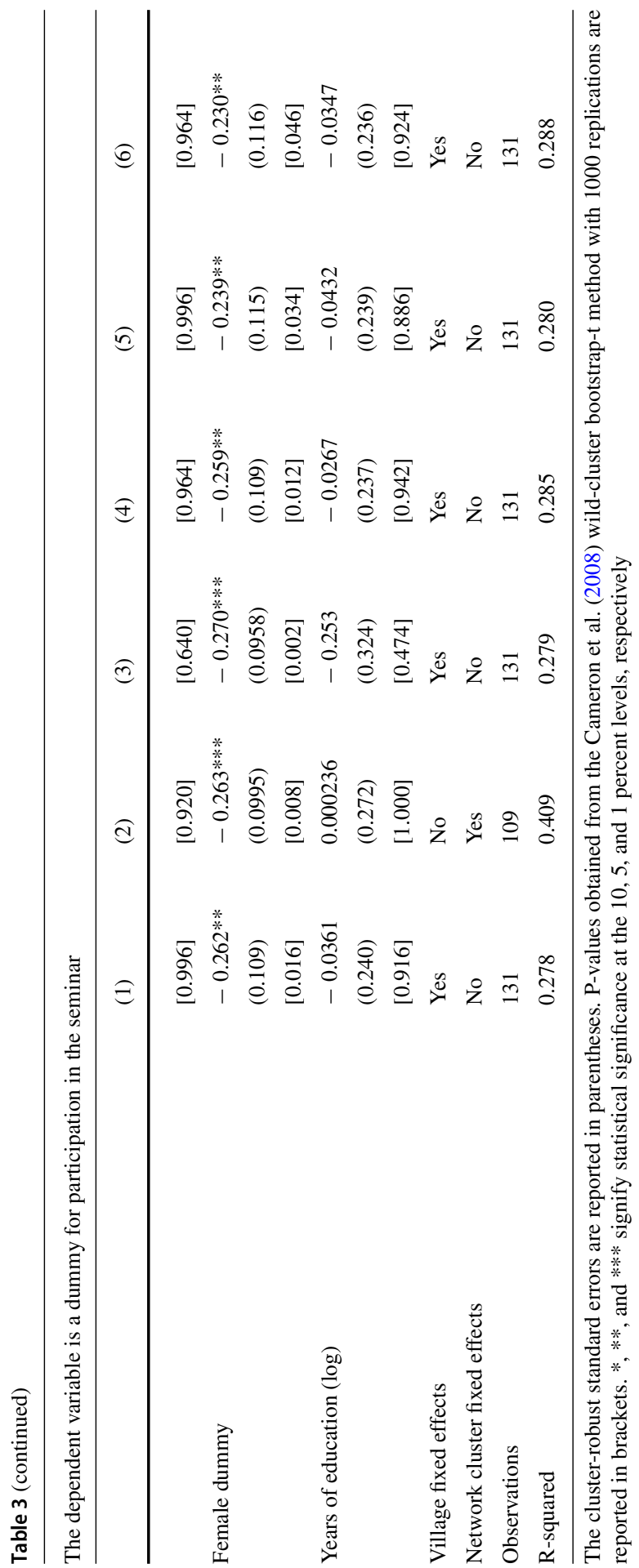


network cluster fixed effects instead of village fixed effects in Eq. (1). The results in column (2) of Table 3 indicate that the estimated coefficient on the number of invited peers is still positive but statistically insignificant. In the benchmark estimations, we use the number of invited peers as our key independent variable, assuming that peer effects are larger when the number of peers is larger. We alternatively use the dummy variable that takes a value of one if the firm has any invited peer and zero otherwise, highlighting the difference between firms with no invited peers and those with any positive number of peers. Column (3) of Table 3 indicates that the estimated coefficient on the dummy is positive but statistically insignificant, a result that is consistent with the benchmark result. Because the number of invited peers varies more than the dummy for invited peers, we will hereafter use the number of invited peers rather than the dummy.

\subsection{Decomposing peer effects}

Subsequently, we decompose peer effects. That is, we estimate the effect of peers who were invited to the earlier seminars, peers who were invited to the seminar on the same day, and peers who were invited to the later seminars. We consider the following linear probability model:

$$
\begin{aligned}
P A R_{i l}= & \alpha_{l}+\beta_{1} I N V_{E A R L Y_{i}}+\beta_{2} I N V_{S A M E_{i}}+\beta_{3} I N V_{L A T E_{i}} \\
& +\delta n_{i l}+\gamma X_{i l}+\zeta D a y_{i}+\lambda \sum_{j \in P_{i l}} X_{j l} / n_{i l}+u_{i l}
\end{aligned}
$$

where $I N V_{-} E A R L Y_{i}$ is the number of firm $i$ 's peers that are invited to the earlier seminars, $I N V_{-} S A M E_{i}$ is the number of firm $i$ 's peers that are invited to the seminar to which firm $i$ is invited, $I N V \_L A T E_{i}$ represents the number of firm $i$ 's peers that are invited to the later seminars, and $u_{i l}$ is the error term. The effect of peers who were invited to the earlier seminars, $\beta_{1}$, represents the sum of their effects through word-ofmouth, a positive effect due to information confirmation, and a negative effect due to information free riding. The effect of peers invited to the same seminar, $\beta_{2}$, constitutes the sum of positive peer effects due to the benefits of face-to-face interactions, a positive effect due to information confirmation, and a negative effect due to information free riding. The effect of peers invited to the later seminars, $\beta_{3}$, represents the sum of the effects due to information confirmation and free riding. Therefore, $\beta_{1}-\beta_{3}$ signifies the peer effect arising from word-of-mouth, and $\beta_{2}-\beta_{3}$ constitutes the peer effect due to the benefits of face-to-face interactions.

The result is shown in column (1) in Table 4. The results demonstrate a positive and statistically significant effect of the number of peers invited to the same seminar but no significant effect of the number of peers invited to the earlier or the later seminars. To address correlated effects more accurately as we did in Sect. 3.1, we estimate an alternative specification, replacing the village fixed effects with network cluster fixed effects in Eq. (2). The result is shown in column (2) in Table 4. The estimated coefficients for the number of peers invited to the seminar on the same day, the number of peers invited to the earlier seminars, and the number of peers invited 


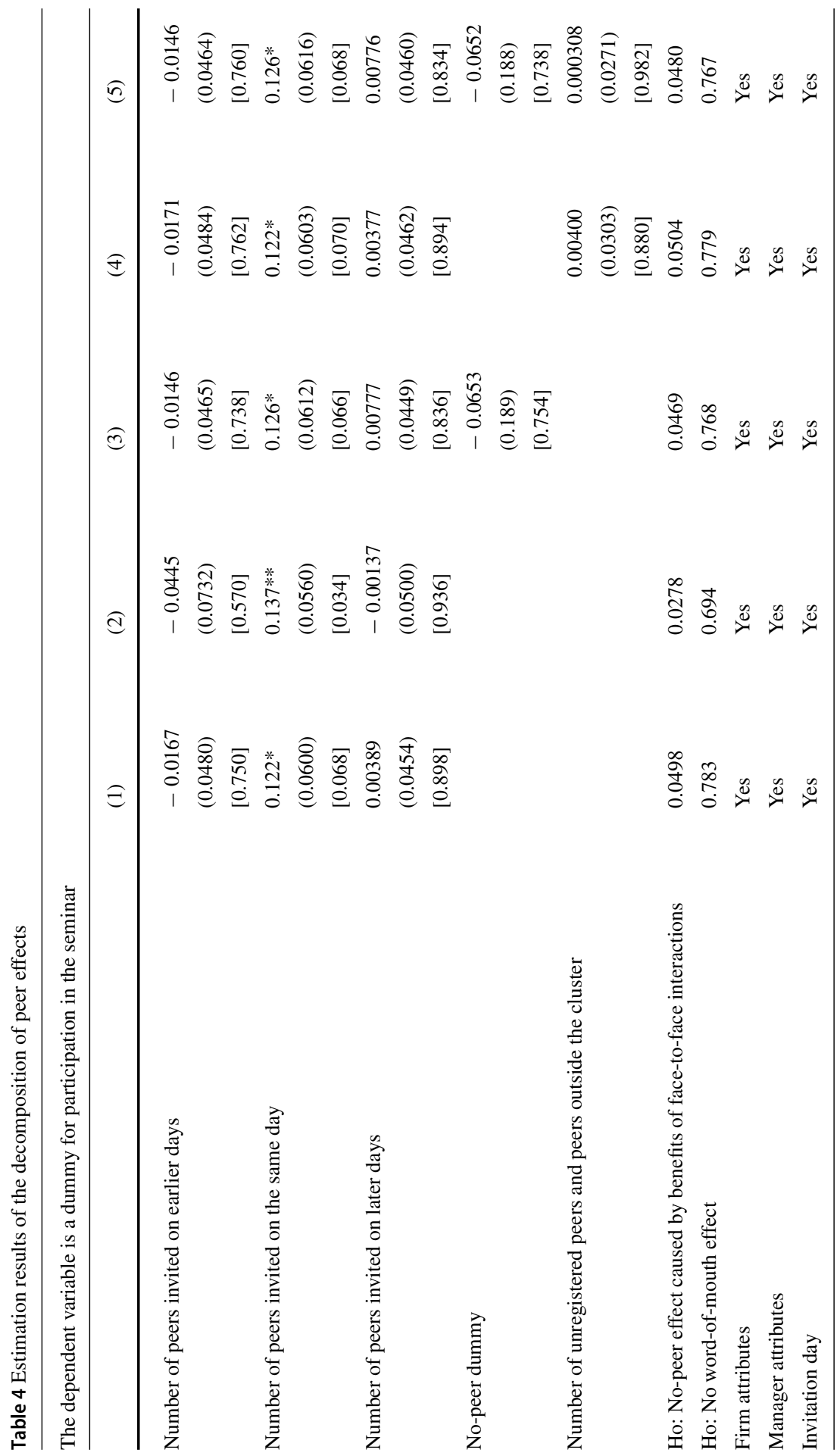




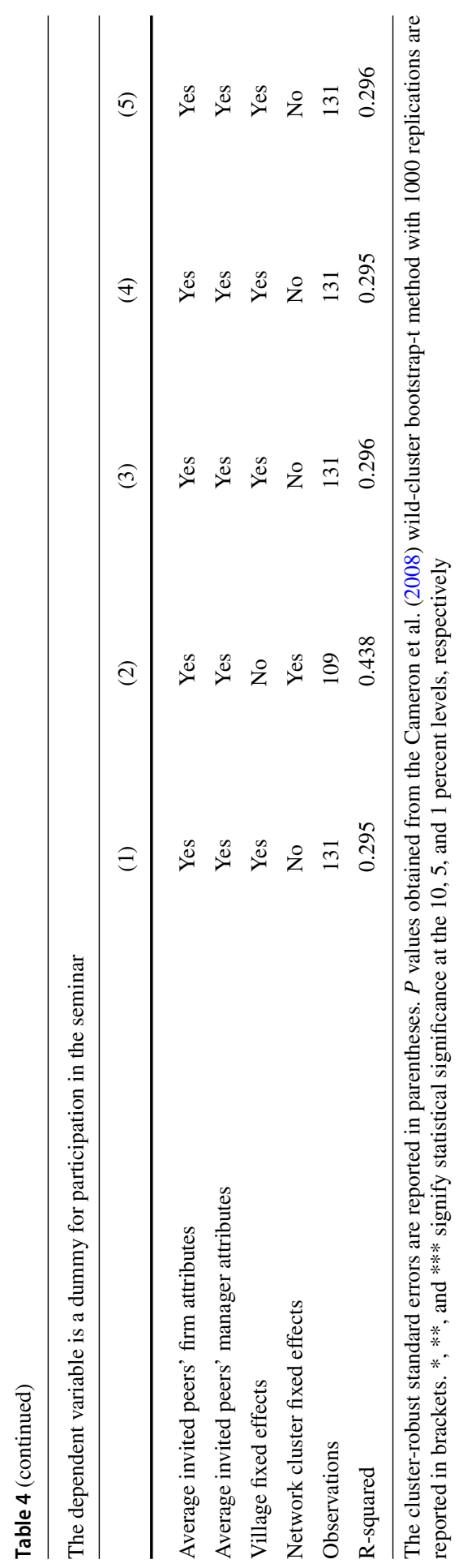


Table 5 Estimation results of the decomposition of peer effects by logit model and probit model

The dependent variable is a dummy for participation in the seminar

\begin{tabular}{|c|c|c|c|c|}
\hline & \multicolumn{2}{|c|}{ Logit model } & \multicolumn{2}{|c|}{ Probit model } \\
\hline & Coef. & $\begin{array}{l}\text { Average marginal } \\
\text { effects }\end{array}$ & Coef. & $\begin{array}{l}\text { Average marginal } \\
\text { effects }\end{array}$ \\
\hline $\begin{array}{l}\text { Number of peers invited } \\
\text { on earlier days }\end{array}$ & $\begin{array}{l}-0.124 \\
(0.325)\end{array}$ & $\begin{array}{l}-0.017 \\
(0.045)\end{array}$ & $\begin{array}{l}-0.034 \\
(0.156)\end{array}$ & $\begin{array}{l}-0.008 \\
(0.038)\end{array}$ \\
\hline $\begin{array}{l}\text { Number of peers invited } \\
\text { on the same day }\end{array}$ & $\begin{array}{l}1.010 * * \\
(0.458)\end{array}$ & $\begin{array}{l}0.151 * * \\
(0.065)\end{array}$ & $\begin{array}{l}0.630 * * \\
(0.256)\end{array}$ & $\begin{array}{l}0.154 * * \\
(0.061)\end{array}$ \\
\hline $\begin{array}{l}\text { Number of peers invited } \\
\text { on later days }\end{array}$ & $\begin{array}{l}0.061 \\
(0.348)\end{array}$ & $\begin{array}{l}0.008 \\
(0.048)\end{array}$ & $\begin{array}{l}0.079 \\
(0.189)\end{array}$ & $\begin{array}{l}0.019 \\
(0.046)\end{array}$ \\
\hline Firm attributes & Yes & & Yes & \\
\hline Manager attributes & Yes & & Yes & \\
\hline Invitation day & Yes & & Yes & \\
\hline $\begin{array}{l}\text { Average invited peers' } \\
\text { firm attributes }\end{array}$ & Yes & & Yes & \\
\hline $\begin{array}{l}\text { Average invited peers' } \\
\text { manager attributes }\end{array}$ & Yes & & Yes & \\
\hline Village fixed effects & Yes & & Yes & \\
\hline Observations & 122 & & 122 & \\
\hline Pseudo R-squared & 0.2689 & & 0.2610 & \\
\hline
\end{tabular}

The cluster-robust standard errors are reported in parentheses. *, **, and $* * *$ signify statistical significance at the 10,5 , and 1 percent levels, respectively

to the later seminars are very similar to those in column (1) in Table $4 .{ }^{3}$ Therefore, using village fixed effects or network cluster fixed effects, i.e., whether controlling for correlated effects less or more accurately, does not affect the estimation results of peer effects in our analysis. As a robustness check, we test whether the results above remain valid if we control for the effect of no peers or the effect of peers not on the list of registered firms. The results are shown in columns (3)-(5) in Table 4. The results remain largely unchanged when controlling for these effects. In addition, because the dependent variable is a dummy variable, we estimated Eq. (2) by applying logit and probit models. The estimated coefficients and average marginal effects are shown in Table 5. The results are very similar to those in column (1) in Table 4.

As a further robustness check, we test whether the results above remain valid if we incorporate other standard measures of centrality in a network, such as the eigenvector, betweenness, and closeness centrality (Jackson 2010), into the set of control variables used in Eq. (2). The results are shown in Table 6. The estimated coefficients of the number of peers invited to the seminar on the same day and of the number of peers

\footnotetext{
3 We checked whether the results shown in Tables 4, 5, and 6 hold if we use network cluster fixed effects instead of village fixed effects in the specifications in Tables 4, 5 and 6 . The estimated results are mostly similar to those in Tables 4, 5 and 6.
} 
Table 6 Estimation results of the decomposition of peer effects incorporating network centrality

The dependent variable is a dummy for participation in the seminar

(1) (2)

2) (3)

(3)

(4)

Number of peers invited on earlier days

$\begin{array}{llll}-0.0125 & -0.0260 & -0.0168 & -0.0175 \\ (0.0467) & (0.0495) & (0.0493) & (0.0472) \\ {[0.822]} & {[0.642]} & {[0.748]} & {[0.748]} \\ 0.120^{*} & 0.119 * & 0.134 * & 0.129 * \\ (0.0594) & (0.0573) & (0.0660) & (0.0618) \\ {[0.070]} & {[0.070]} & {[0.076]} & {[0.062]} \\ 0.00686 & 0.00169 & 0.0101 & 0.0144 \\ (0.0486) & (0.0441) & (0.0446) & (0.0478) \\ {[0.896]} & {[0.946]} & {[0.818]} & {[0.782]}\end{array}$

Centrality measure

Number of peers (degree)

Eigenvector

$\begin{array}{lll}-0.0252 & -0.0143 & -0.0432 * * \\ (0.0179) & (0.0166) & (0.0169) \\ {[0.180]} & {[0.302]} & {[0.002]}\end{array}$

$-0.112$

(0.174)

[0.504]

$-1.470$

(1.374)

[0.378]

Closeness

Ho: No-peer effect caused by benefits of face-to-face interactions

Ho: No word-of-mouth effect

Firm attributes

Manager attributes

Invitation day

Average invited peers' firm attributes

Average invited peers' manager attributes

Village fixed effects

Observations

R-squared

\begin{tabular}{llll} 
& & 1.059 & 1.190 \\
& & $(0.939)$ & $(1.003)$ \\
& & {$[0.318]$} & {$[0.282]$} \\
0.0618 & 0.0592 & 0.0500 & 0.0718 \\
0.796 & 0.718 & 0.735 & 0.695 \\
Yes & Yes & Yes & Yes \\
Yes & Yes & Yes & Yes \\
Yes & Yes & Yes & Yes \\
Yes & Yes & Yes & Yes \\
Yes & Yes & Yes & Yes \\
Yes & Yes & Yes & Yes \\
131 & 131 & 131 & 131 \\
0.296 & 0.300 & 0.300 & 0.307 \\
\hline
\end{tabular}

The cluster-robust standard errors are reported in parentheses. $P$ values obtained from the Cameron et al. (2008) wild-cluster bootstrap-t method with 1000 replications are reported in brackets. *, **, and *** signify statistical significance at the 10,5 , and 1 percent levels, respectively 
invited to the earlier seminars and of the number of peers invited to the later seminars are mostly similar to those in Table 4 even when we incorporate other centrality measures into the analysis. However, the estimated coefficients on all of these centrality measures are not statistically significant. These results imply that after we control for the simplest centrality measure, the degree to which other centrality measures do not necessarily affect firms' participation decisions and therefore may not be incorporated into the estimations.

Based on the above argument, we separate peer effects into those arising from the benefits of face-to-face interactions, those arising from word-of-mouth, and the sum of the other two effects (a positive effect due to information confirmation and a negative effect due to information free riding). We conduct Wald tests to examine the null hypothesis that the peer effect arising from word-of-mouth is zero $\left(\beta_{1}-\beta_{3}=0\right)$ and the null hypothesis that the peer effect due to the benefits of face-to-face interactions is zero $\left(\beta_{2}-\beta_{3}=0\right)$. The two rows in the lower part of Tables 4 and 6 show $p$ values associated with these Wald tests. ${ }^{4}$ The null hypothesis on peer effects arising from word-of-mouth is not rejected statistically in all specifications in Tables 4 and 6. Therefore, we find no evidence that word-of-mouth from peers did not promote participation in the seminars. A possible reason for the lack of a word-of-mouth effect is that participants had no time to spread information about the seminars because the seminars were held on three consecutive days and ended at 4:00 p.m. or 4:30 p.m. each day. In contrast, the null hypothesis on the peer effect due to benefits of faceto-face interactions is rejected at the 5-percent level in all specifications in Tables 4 and 6 . These results suggest that firm managers are more willing to participate in the seminars to enjoy face-to-face communication with their peers there. Moreover, the insignificant effect of the number of peers invited to the seminar on the later days in Tables 4, 5, and 6 implies that the sum of the positive effect due to information confirmation and the negative effect due to information free riding is zero, although we cannot further distinguish between the two.

As discussed in Sect. 2.3, five invited firms participated in a "wrong" seminar to which they were not invited. We checked whether the results from the estimations and Wald tests hold if we drop these five firms from the sample. To save space, we do not show the full estimation results here, but they are mostly similar to the results in Tables 4, 5, and 6 except that the estimated coefficients of the number of peers who invited to the seminar on the same day are smaller (but still statistically significant) than those in Tables 4, 5, and 6. The results of the Wald test using the smaller sample are essentially the same as those in Tables 4 and 6.

\subsection{Heterogeneity}

We further investigate the possibility that peer effects are heterogeneous depending on firm attributes, particularly focusing on managers' gender and exporting activities. We incorporate the interaction term between the number of invited peers and each of these firm attributes to Eq. (1) and show the results in columns (3)-(5) in Table 3. The

\footnotetext{
4 The results of these Wald tests are the same when we replace village fixed effects with network cluster fixed effects in all specifications in Tables 4 and 6.
} 
estimated coefficient for the interaction terms between the number of invited peers and share of exporting is negative and statistically significant, while the estimated coefficient for the interaction terms with the female dummy is not significant. Thus, total peer effects on participation in the seminar are negative for exporting firms.

Similarly, we investigate heterogeneity in decomposed peer effects by incorporating interaction terms between the number of peers invited to the earlier, the same, and the later seminars and firm attributes (i.e., the manager's gender and the share of exports) into Eq. (2). The results are shown in columns (1)-(3) in Table 7. The estimated coefficient of the interaction term between the number of peers invited to the seminar on the same day and the share of exports is negative and statistically significant, whereas other interaction terms are not statistically significant. Therefore, the peer effect arising from the benefits of face-to-face interactions for exporting firms is weaker than that for nonexporting firms.

\section{Discussion and conclusion}

By utilizing an RCT in traditional clusters of apparel and textile SMEs in Vietnam, we investigate peer effects on firms' participation in seminars focused on export promotion. We use the number of randomly invited peers to identify such peer effects. We further decompose the invited peers into peers invited to a seminar on the earlier day, peers invited to seminars on the same day, and peers invited to seminars on the later days. In this way, we can isolate peer effects caused by the benefits of face-to-face interactions and peer effects arising from word-of-mouth from the sum of the positive effect of information confirmation and the negative effect of information free riding on peers' information.

The results in Tables 3, 4, 5, 6 and 7 can be summarized as follows. First, the identified peer effect caused by the benefits of face-to-face interactions is large: an additional peer invited to the seminar on the same day increases a firm's probability of participation in the seminar by 12.2 percentage points (column (1) in Table 4), whereas the average participation rate is only 25.2 percent (Table 2). However, the peer effect caused by the benefits of face-to-face interactions is weakened for exporting firms' managers. Second, we do not find evidence that word-of-mouth from peers led to peer effects in our case. Third, theoretically, there may be two other types of peer effects: a positive effect due to information confirmation among peers and a negative effect due to information free riding on peers' information. Our empirical results suggest that the two opposing effects may cancel each other out or may both be negligible.

The positive peer effects found in this study imply the possibility of multiple equilibria across the group, as argued in Card and Giuliano (2013): Firms are better off participating in a seminar if many peers participate, but they are worse off if only a few peers participate. In our experiment, we indeed found some villages in which most of the invited firms did not participate in any seminar and other villages in which most of the invited firms participated in some seminars (see Fig. 2).

The actual situation in this study is more complicated, however, as we find positive effects of peers invited to a seminar on the same day but no effect of peers invited to the earlier seminars and of peers invited to the later seminars. In the latter cases, 
Table 7 Heterogeneity in decomposition of peer effects

The dependent variable is a dummy for participation in the seminar

\begin{tabular}{|c|c|c|c|}
\hline & (1) & $(2)$ & (3) \\
\hline \multirow[t]{3}{*}{ Number of peers invited on earlier days } & -0.0370 & -0.0205 & -0.0357 \\
\hline & $(0.0464)$ & $(0.0422)$ & $(0.0421)$ \\
\hline & {$[0.416]$} & [0.694] & {$[0.364]$} \\
\hline \multirow{3}{*}{$\begin{array}{l}\text { Number of peers invited on the earlier days } * \text { female } \\
\text { dummy }\end{array}$} & 0.0521 & & 0.0281 \\
\hline & $(0.131)$ & & $(0.122)$ \\
\hline & [0.694] & & [0.810] \\
\hline \multirow{3}{*}{$\begin{array}{l}\text { Number of peers invited on the earlier days * share of } \\
\text { exports }\end{array}$} & & 0.00117 & 0.000763 \\
\hline & & $(0.000848)$ & $(0.000879)$ \\
\hline & & {$[0.148]$} & {$[0.328]$} \\
\hline \multirow[t]{3}{*}{ Number of peers invited on the same day } & $0.162 *$ & 0.115 & $0.150 *$ \\
\hline & $(0.0705)$ & $(0.0657)$ & $(0.0709)$ \\
\hline & {$[0.060]$} & {$[0.156]$} & {$[0.080]$} \\
\hline \multirow{3}{*}{$\begin{array}{l}\text { Number of peers invited on the same day } * \text { female } \\
\text { dummy }\end{array}$} & -0.0202 & & 0.0373 \\
\hline & $(0.195)$ & & $(0.192)$ \\
\hline & {$[0.950]$} & & {$[0.822]$} \\
\hline \multirow[t]{3}{*}{$\begin{array}{l}\text { Number of peers invited on the same day * share of } \\
\text { exports }\end{array}$} & & $-0.00200^{* *}$ & - \\
\hline & & $(0.000975)$ & $(0.000942)$ \\
\hline & & {$[0.034]$} & {$[0.002]$} \\
\hline \multirow[t]{3}{*}{ Number of peers invited on later days } & -0.0235 & 0.00241 & -0.0228 \\
\hline & $(0.0448)$ & $(0.0473)$ & $(0.0490)$ \\
\hline & {$[0.652]$} & {$[0.930]$} & {$[0.642]$} \\
\hline \multirow{3}{*}{$\begin{array}{l}\text { Number of peers invited on the later days } * \text { female } \\
\text { dummy }\end{array}$} & 0.160 & & 0.152 \\
\hline & $(0.109)$ & & $(0.114)$ \\
\hline & {$[0.174]$} & & {$[0.234]$} \\
\hline \multirow{3}{*}{$\begin{array}{l}\text { Number of peers invited on the later days * share of } \\
\text { exports }\end{array}$} & & -0.00002 & -0.00001 \\
\hline & & $(0.000581)$ & $(0.000563)$ \\
\hline & & {$[0.972]$} & {$[0.974]$} \\
\hline $\begin{array}{l}\text { Ho: No-peer effect caused by benefits of face-to-face } \\
\text { interactions }\end{array}$ & 0.0176 & 0.172 & 0.0692 \\
\hline Ho: No word-of-mouth effect & 0.857 & 0.723 & 0.858 \\
\hline Firm attributes & Yes & Yes & Yes \\
\hline Manager attributes & Yes & Yes & Yes \\
\hline Invitation day & Yes & Yes & Yes \\
\hline Average invited peers' firm attributes & Yes & Yes & Yes \\
\hline Average invited peers' manager attributes & Yes & Yes & Yes \\
\hline
\end{tabular}


Table 7 (continued)

The dependent variable is a dummy for participation in the seminar

Village fixed effects

Observations

R-squared
(1)

(2)

(3)

$\begin{array}{lll}\text { Yes } & \text { Yes } & \text { Yes } \\ 131 & 131 & 131 \\ 0.316 & 0.309 & 0.327\end{array}$

The cluster-robust standard errors are reported in parentheses. $P$ values obtained from the Cameron et al. (2008) wild-cluster bootstrap-t method with 1000 replications are reported in brackets. *, **, and *** signify statistical significance at the 10,5 , and 1 percent levels, respectively

depending on how many firms in the village were invited to the seminar on each of the three days, the participation rate within the village varied. Suppose, for example, that three firms that are linked to each other in a village were invited to the seminar on the first day but that only one firm in the same village was invited on each of the other two days. Then, depending on their beliefs about their peers' behaviors, all or none of the former three firms would participate. However, the last two might not participate, which would lead to a participation rate of either 75 percent or 0 percent.

Based on this conjecture, we expect that the take-up rate among invited firms varies substantially across villages, although it may skew toward zero. Panel a of Fig. 3 shows the distribution of the take-up rate among the invited firms in each village. The dominant take-up rate is approximately 10-20 percent, but there are a few villages with rates of 50-70 percent. Panel b shows the take-up rate among invited firms with invited peers in the ego network of each invited firm, i.e., the invited firm and its invited peers. However, the distribution of the other firms is dispersed widely, from 10 to 100 percent, while the dominant take-up rate is 0 percent. Some firm networks have a high take-up rate of over 80 percent. These dispersed distributions are consistent with the argument that multiple equilibria exist as a result of peer effects.

Our results provide an important policy implication. The evidence of positive peer effects mostly due to the benefits of face-to-face interactions provides an explanation for the fact that the take-up rate of social and business seminars is often low (Bruhn and Zia 2013; McKenzie and Woodruff 2014). The take-up ratio of any program involving a collective face-to-face component can be low when invitees expect that their peers will not participate. Therefore, to increase the take-up ratio, the organizer needs to fully utilize peer effects arising from the benefits of face-to-face interactions and invite many firms in a particular social or business group rather than a few firms from each of many groups. Social network studies often argue that a strategy to effectively utilize social networks for information diffusion is to invite social program opinion leaders or people in visibly influential positions, hoping that their message will spread to others (Valente 2017). Our study shows another strategy to effectively raise the take-up ratios of social and business programs, although it does not necessarily reject the role of opinion leaders in information diffusion.

Finally, we note an important caveat. Although the existence of information free riding is an important academic and policy issue, we cannot distinguish between the 
Fig. 2 Interfirm social network

Village 1

Village 2

and participation in the

seminars. Notes: Red, green, and

yellow circles indicate firms that participated in a seminar, those that were invited but did not participate in any seminar, and those that were not invited to any seminar, respectively. (Color figure online)

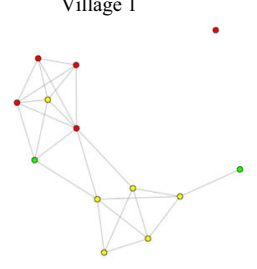

Village 3

Village 4

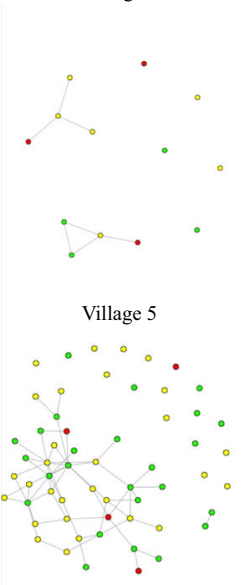

Village 7

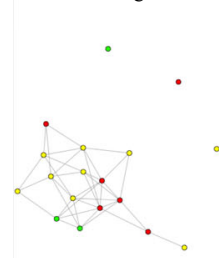

Village 9

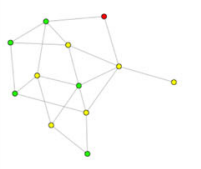

Village 11

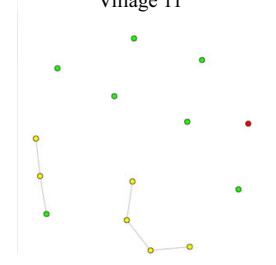

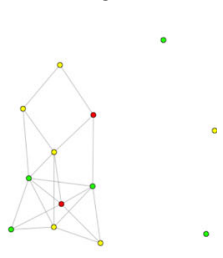

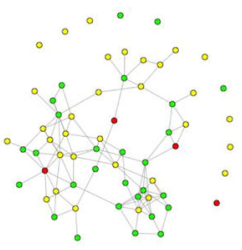

Village 6

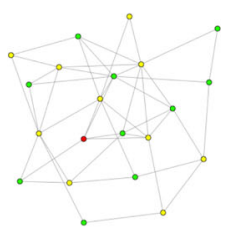

Village 8

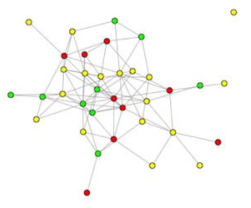

Village 10

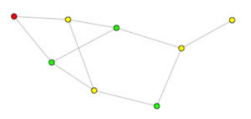


Fig. 3 Distribution of the take-up rate. Notes: This figure shows the distribution of the take-up rate among the invited firms in the ego network of each of the 131 invited firms studied in the regressions, i.e., an invited firm and its invited peers. Firms that have no peers are excluded from Fig. 3b

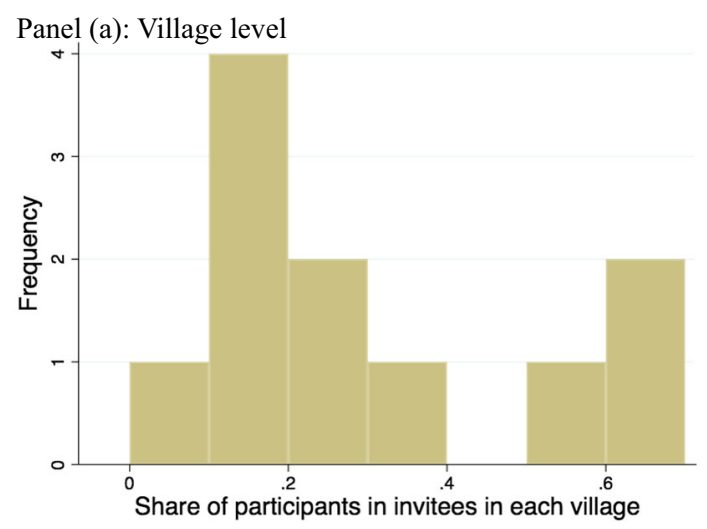

Panel (b): Firm level

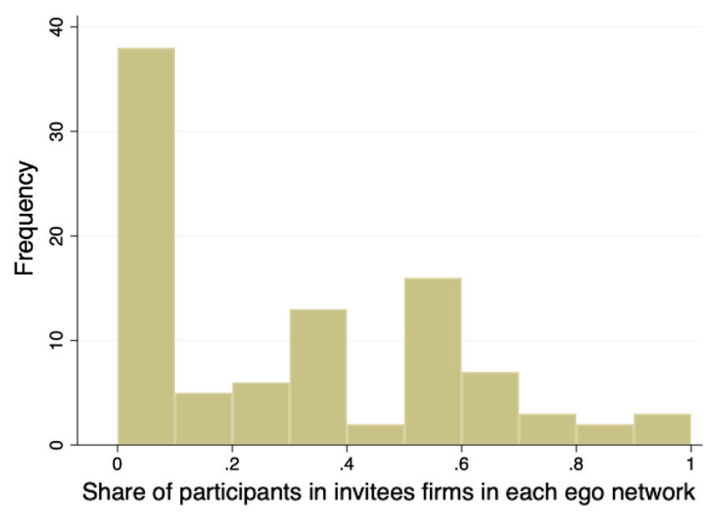

effect of information free riding and the effect of information confirmation in this study. One way to decompose the peer effect of information free riding is to utilize variation in the difficulty of seminar subjects. If a seminar provides information that is difficult to understand (for example, procedures for exporting activities), the negative peer effect of information free riding may be minimal because it is difficult to obtain this information from others without participating in the seminar. In contrast, information free riding is prominent if the subject of the seminar is important but easy to understand (for example, procedures for applying for subsidies). By comparing peer effects across these situations, we may decompose the peer effect of information free riding. We leave this issue to future research.

Acknowledgements This research was conducted as part of a project entitled 'Firms' Domestic and International Networks,' which was undertaken at the Research Institute of Economy, Trade and Industry (RIETI). The authors would like to thank the JSPS Kakenhi Grant (No. 25101003, 26245037, and 17K13738) and Waseda University for their financial support. The authors also wish to thank two anonymous referees, Ichimura Hidehiko, Tatsuo Hatta, Charles Yuji Horioka, Takeshi Aida, Tadao Hoshino, Shinsuke Uchida, Yuki Higuchi, Masayuki Morikawa, Yasuyuki Sawada, Junichi Yamazaki, Pedro Franco, Takashi Kurosaki, Tsunehiro Otsuki, Yukichi Mano, Yutaka Arimoto, Mari Tanaka, Kazuya Masuda, Keisuke Kawata, Eiichi Tomiura, Makoto Yano, and the seminar participants at Keio University, RIETI, Hitotsubashi University, Waseda University, Musashi University, Tokyo Labor Economics Workshop, Nagoya 
City University, the University of Sydney, Tsukuba University, Osaka University, 12th Annual Conference on Economic Growth and Development at Indian Statistical Institute and the workshop on Global Economic Issues and Regional Policy Responses at Korea University for their helpful comments. The opinions that are expressed and the arguments that are employed in this paper are the sole responsibility of the authors and do not necessarily reflect those of RIETI, Waseda University, Kindai University, Hanyang University, the University of Sydney, or any institution with which the authors are affiliated.

Authors' Contribution In this manuscript, we investigate how firm managers' decisions to participate in seminars on export promotion are affected by their information exchange peers, utilizing a randomized controlled trial (RCT) in traditional clusters of apparel and textile firms in Northern Vietnam. Using the number of randomly invited peers, we find that firms' participation in the seminars were encouraged by their peers' participation. Moreover, the unique feature of our experiment enables us to decompose peer effects. Specifically, we separate peer effects through benefits of face-to-face interactions, word-of-mouth from other two effects, i.e., positive effects through information confirmation with participating peers and negative effects through information free riding. Our result suggests that peer effects partly arise from benefits of face-to-face interactions. Although previous empirical studies have examined peer effects, our paper contributes to the literature in the following three respects. First, this paper is the first attempt to identify firm managers' decision to participate in business programs. Second, we define a particular firm's peers according to firms' actual links to the exchange of business information, rather than group membership. Third, we decompose peer effects on firm managers' decisions. Because these issues, in particular the third issue, have rarely been examined in the literature, we believe that this manuscript fits the extremely high standard of Empirical Economics.

Funding This study was funded by the JSPS Kakenhi Grant (No. 25101003, 26245037, and 17K13738).

Availability of data and material If required, we would be happy to provide all primary data, codes, and programs used in this paper for the purpose of replication.

Code availability If required, we would be happy to provide all primary data, codes, and programs used in this paper for the purpose of replication.

\section{Declarations}

Conflict of interest All authors declare that he/she has no conflict of interest.

Ethics approval This article does not contain any studies with human participants performed by any of the authors.

Open Access This article is licensed under a Creative Commons Attribution 4.0 International License, which permits use, sharing, adaptation, distribution and reproduction in any medium or format, as long as you give appropriate credit to the original author(s) and the source, provide a link to the Creative Commons licence, and indicate if changes were made. The images or other third party material in this article are included in the article's Creative Commons licence, unless indicated otherwise in a credit line to the material. If material is not included in the article's Creative Commons licence and your intended use is not permitted by statutory regulation or exceeds the permitted use, you will need to obtain permission directly from the copyright holder. To view a copy of this licence, visit http://creativecommons.org/licenses/ by $/ 4.0 /$.

\section{References}

Angrist JD, Lang K (2004) Does school integration generate peer effects? Evidence from Boston's Metco program. Am Econ Rev 94:1613-1634. https://doi.org/10.1257/0002828043052169

Aral S, Walker D (2011) Creating social contagion through viral product design: a randomized trial of peer influence in networks. Manag Sci 57:1623-1639. https://doi.org/10.1287/mnsc.1110.1421 
Banerjee A, Chandrasekhar AG, Duflo E, Jackson MO (2013) The diffusion of microfinance. Science 341:1236498. https://doi.org/10.1126/science.1236498

Bertrand M, Mullainathan S, Shafir E (2004) A behavioral-economics view of poverty. Am Econ Rev 94:419-423. https://doi.org/10.1257/0002828041302019

Blume LE, Brock WA, Durlauf SN, Ioannides YM (2011) Identification of social interactions. In: Benhabib J, Bisin A, Jackson MO (eds) Handbook of social economics. Elsevier, Amsterdam, pp 853-964

Bramoullé Y, Djebbari H, Fortin B (2009) Identification of peer effects through social networks. J Econ 150:41-55. https://doi.org/10.1016/j.jeconom.2008.12.021

Bramoullé Y, Djebbari H, Fortin B (2020) Peer effects in networks: a survey. Ann Rev Econ 12:603-629. https://doi.org/10.1146/annurev-economics-020320-033926

Bruhn M, Zia B (2013) Stimulating managerial capital in emerging markets: the impact of business training for young entrepreneurs. J Dev Eff 5:232-266. https://doi.org/10.1080/19439342.2013.780090

Bursztyn L, Ederer F, Ferman B, Yuchtman N (2014) Understanding mechanisms underlying peer effects: evidence from a field experiment on financial decisions. Econometrica 82:1273-1301. https://doi.org/ 10.3982/ECTA11991

Cai J, Szeidl A (2018) Interfirm relationships and business performance. Q J Econ 133:1229-1282. https:// doi.org/10.1093/qje/qjx049

Calvó-Armengol A, Patacchini E, Zenou Y (2009) Peer effects and social networks in education. Rev Econ Stud 76:1239-1267. https://doi.org/10.1111/j.1467-937X.2009.00550.x

Cameron G, Miller, (2008) Bootstrap-based improvements for inference with clustered errros. Rev Econ Stat 90:414-427. https://doi.org/10.1162/rest.90.3.414

Card D, Giuliano L (2013) Peer effects and multiple equilibria in the risky behavior of friends. Rev Econ Stat 95:1130-1149. https://doi.org/10.1162/REST_a_00340

Carrell SE, Sacerdote BI, West JE (2011) From natural variation to optimal policy? The lucas critique meets peer effects. National Bureau of Economic Research, Cambridge, MA

Centola D (2010) The spread of behavior in an online social network experiment. Science 329:1194-1197. https://doi.org/10.1126/science. 1185231

Currie JM (2006) The take up of social benefits. In: Quigley JM, Card D (eds) Public policy and the distribution of income. Russell Sage Foundation, New York, NY, pp 80-148

Dahl GB, Løken KV, Mogstad M (2014) Peer effects in program participation. Am Econ Rev 104:2049-2074. https://doi.org/10.1257/aer.104.7.2049

De Giorgi G, Pellizzari M, Redaelli S (2010) Identification of social interactions through partially overlapping peer groups. Am Econ J Appl Econ 2:241-275. https://doi.org/10.1257/app.2.2.241

Duflo E, Saez E (2003) The role of information and social interactions in retirement plan decisions: evidence from a randomized experiment. Q J Econ 118:815-842. https://doi.org/10.1162/00335530360698432

Durlauf SN (2006) Groups, social influences, and inequality. In: Bowles S, Durlauf S, Hoff K (eds) Poverty traps. Princeton University Press, Princeton, NJ, pp 141-175

Fafchamps M, Quinn S (2018) Networks and manufacturing firms in Africa: results from a randomized field experiment. World Bank Econ Rev 32:656-675. https://doi.org/10.1093/wber/lhw057

Falk A, Ichino A (2006) Clean evidence on peer effects. J Labor Econ 24:39-57. https://doi.org/10.1086/ 497818

Higuchi Y, Nam VH, Sonobe T (2015) Sustained impacts of Kaizen training. J Econ Behav Organ 120:189-206. https://doi.org/10.1016/j.jebo.2015.10.009

Jackson MO (2010) Social and economic networks. Princeton University Press, Princeton, NJ

Jackson MO, Zenou Y (2015) Games on networks. In: Young HP, Zamir S (eds) Handbook of game theory with economic applications. Elsevier, Amsterdam, pp 95-163

Kim YR, Todo Y, Shimamoto D, Matous P (2018) Are seminars on export promotion effective? Evidence from a randomised controlled trial. World Econ 41:2954-2982. https://doi.org/10.1111/twec.12658

Manski CF (1993) Identification of endogenous social effects: the reflection problem. Rev Econ Stud 60:531-542. https://doi.org/10.2307/2298123

McKenzie D, Woodruff C (2014) What are we learning from business training and entrepreneurship evaluations around the developing world? World Bank Res Obs 29:48-82. https://doi.org/10.1093/wbro/ $1 \mathrm{kt} 007$

Sacerdote B (2001) Peer effects with random assignment: results for dartmouth roommates. Q J Econ 116:681-704. https://doi.org/10.1162/00335530151144131

Sacerdote B (2014) Experimental and quasi-experimental analysis of peer effects: two steps forward? Ann Rev Econ 6:253-272. https://doi.org/10.1146/annurev-economics-071813-104217 
Valente TW (2017) Putting the network in network interventions. Proc Natl Acad Sci U S A 114:9500-9501. https://doi.org/10.1073/pnas.1712473114

Zimmerman DJ (2003) Peer effects in academic outcomes: evidence from a natural experiment. Rev Econ Stat 85:9-23. https://doi.org/10.1162/003465303762687677

Publisher's Note Springer Nature remains neutral with regard to jurisdictional claims in published maps and institutional affiliations. 